\title{
LA-UR-95- 4383
}

Title:
Author(s):

LASER-INDUCED REACTIONS IN A DEEP ULTRA

VIOLET RESIST SYSTEM: STUDIED WITH PICOSECOND INFRARED SPECTROSCOPY

$$
\because F C P B D
$$

\section{FEB 151906 \\ OSTI}

T. Lippert, CST-1

A. Koskelo, CST-1

P.O. Stoutland, CST-6

MRS Fall Meeting, 1995

Symposium B

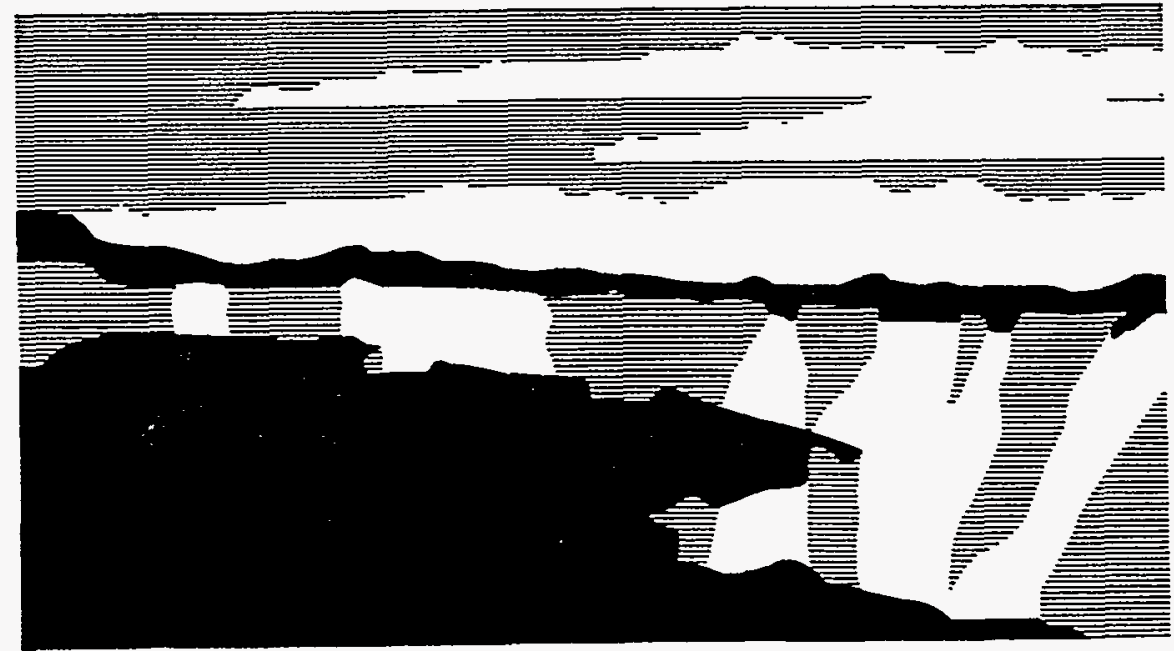

Los Alamos National Laboratory, an affirmative action/equal opportunity employer, is operated by the University of California for the U.S. Department of Energy under contract W-7405-ENG-36. By acceptance of this article, the publisher recognizes that the U.S. Government retains a nonexciusive, royalty-free license to publish or reproduce the published form of this contribution, or to allow others to do so, for U.S. Govemment purposes. The Los Alamos National Laboratory requests that the publisher identify this articie as work performed under the auspices of the U.S. Department of Energy. 


\title{
Laser-induced Reactions in a Deep UV Resist System: Studied with Picosecond Infrared Spectroscopy
}

\author{
T. Lippert, A. Koskelo, P. O. Stoutland \\ Division of Chemical Science and Technology, Mail Stop J-567, Los Alamos National \\ Laboratory, Los Alamos, NM 87545, lippert@lanl.gov
}

\section{ABSTRACT}

One of the most technologically important uses of organic photochemistry is in the imaging industry where radiation-sensitive organic monomers and polymers are used in photoresists. A widely-used class of compounds for imaging applications are diazoketones; these compounds undergo a photoinduced Wolff rearrangement to form a ketene intermediate which subsequently hydrolyses to a base-soluble, carboxylic acid. Another use of organic molecules in polymer matrices is for dopant induced ablation of polymers. As part of a program to develop diagnostics for laser-driven reactions in polymer matrices, we have investigated the photoinduced decomposition of 5-diazo-2,2-dimethyl-1,3-dioxane-4,6-dione (5-diazo Meldrum's acid, $D M)$ in a PMMA matrix using picosecond infrared spectroscopy. In particular, irradiation of DM with a $60 \mathrm{ps} 266 \mathrm{~nm}$ laser pulse results in immediate bleaching of the diazo infrared band $(v=$ $\left.2172 \mathrm{~cm}^{-1}\right)$. Similarly, a new band appears within our instrument response at $2161 \mathrm{~cm}^{-1}(\mathrm{FWHM}$ $=29 \mathrm{~cm}^{-1}$ ) and is stable to greater than $6 \mathrm{~ns}$.; we assign this band to the ketene photoproduct of the Wolff rearrangement. Using deconvolution techniques we estimate a limit for its rate of formation of $\tau<20 \mathrm{ps}$. The linear dependence of the absorbance change with the pump power $(266 \mathrm{~nm})$ even above the threshold of ablation suggest that material ejection take place after $6 \mathrm{~ns}$.

\section{INTRODUCTION}

One of the most technologically important uses of organic photochemistry is in the imaging industry where radiation-sensitive organic monomers and polymers are used in photoresists. ${ }^{1}$ Common examples include systems in which photochemically formed acids become soluble in aqueous base (i.e. positive photoresists) ${ }^{2}$ and where organic dopants sensitize a polymer towards ablation. ${ }^{3}$ The chemistry which occurs in these systems is the basis for the manufacture of high-density electronic circuits, as well as for the production of printing plates.

One of the most widely-used class of compounds for imaging applications are diazoketones. ${ }^{4}$ These compounds undergo a photoinduced Wolff ${ }^{5}$ rearrangement to form a ketene intermediate which subsequently hydrolyses to a base-soluble carboxylic acid. ${ }^{6}$ As part of a program to develop diagnostics for laser-driven reactions in polymer matrices ${ }^{7}$, we have investigated the photo-induced decomposition of 5-diazo-2,2-dimethyl-1;3-dioxane-4,6-dione (5diazo Meldrum=s:acid; DDM in a'PMMA matrix. This particular diazoketone is sensitive to deep UV (200-260 nm) making it suitable for high : resolution lithographic applications 8 - It has historically been difficult to study the-chemistry:of-such resists as many of the-intermediates are short-lived and absorb only in the UV. Recent advances in ultrafast infrared spectroscopy, however, now allow us to directly examine the initial steps occurring in UV photoresists with infrared spectroscopy. Herein, we describe the first room temperature observation of intermediates in the photochemistry of DM with ultrafast infrared spectroscopy.

Shown below is the generally accepted mechanism for the photodecomposition of diazo Meldrum's acid. ${ }^{9}$ 


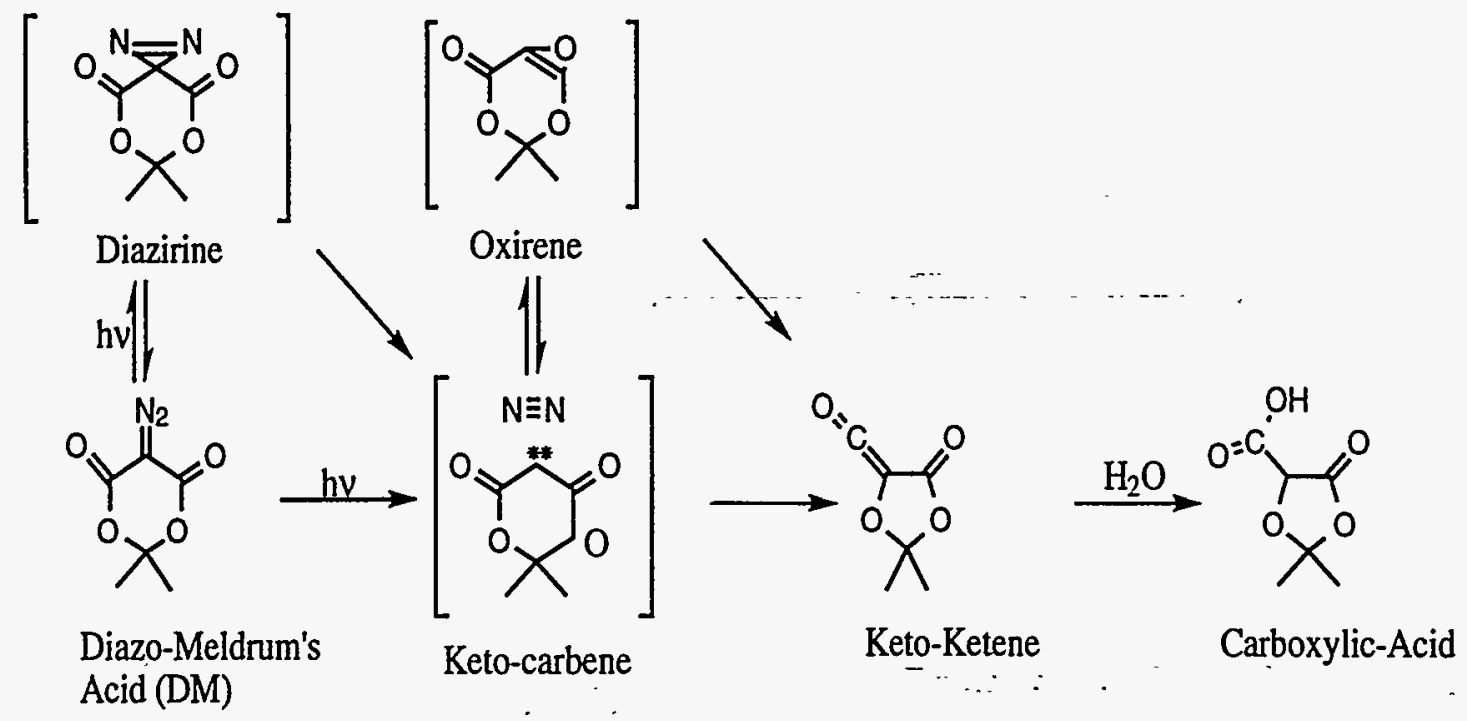

Reaction scheme of the photochemistry of Diazo Meldrums Acid.

:It is widely believed that the initial event is loss of nitrogen and formation of a keto-ketene, most jlikely through a short-lived carbene intermediate. This keto-ketene is hydrolzed by water present in the polymeric matrix to form a ketenehydrate 10 and finally a carboxylic acid. Various other intermediates have also been discussed. For example, it has been reported that isomerization to a diazirine may take place ${ }^{11}$, and that a oxirene ${ }^{12}$ may also be present. For resist applications the key species is the carboxylic acid which results in the resist being base soluble.

For ablation applications, the ketene of DM (and its rate of formation and lifetime) is important as it has been reported to be involved in a multiple photon cyclic absorption process leading to heating and ultimately ablation. ${ }^{9}$ Room-temperature transient experiments have suggested that the keto-ketene forms within $200 \mathrm{~ns}^{13}$, and is hydrolyzed on a seconds timescale. Low temperature experiments coupled with infrared spectroscopy have also identified the ketoketene intermediate $\left(v\right.$ ketene $\left.=2143 \mathrm{~cm}^{-1}\right) .{ }^{14}$ Nevertheless there are only limited data about reactions in polymer matrices at room temperature available.

\section{EXPERIMENTAL}

We have examined the photodecompositon of DM in a PMMA matrix ${ }^{15}$ with picosecond infrared spectroscopy. The general experimental procedure has been described previously 16 and shown in Fig. 1.

Briefly, our infrared probe pulse, tunable from $2900-1800 \mathrm{~cm}^{-1}$, is generated by difference frequency mixing a tunable amplified dye laser pulse (ca. $600 \mathrm{~nm}, 5 \mathrm{ps)}$ with the doubled $532 \mathrm{~nm}$ output of a regenerative YAG amplifier. Our excitation pulse is the frequency quadrupled output $(266 \mathrm{~nm}, 60 \mathrm{ps})$ of the regenerative amplifier. Using conventional deconvolution techniques, we can typically resolve 20 ps events. Time rèsolution is obtained by optical delay, and is variabie from 0 to 6 ñs. Sample consist of 3 jum thick cọtings ó PMMA (Aldrich, $\left.\mathrm{M}_{\mathrm{W}}=120,000\right)$ doped with DM (TCI Ámerica, ca. $20 \%$ by weight) on poly propylene sheets. ${ }^{17}$ The sheets a are held-taut with a-metad frame, and are-translated with a computer controlled stepper motor such that each Iocation on the film is subjected to only a single laser shot. Both pump on and pump off data are taken which allow us to convert our data into $\Delta \mathrm{A}$ units. 


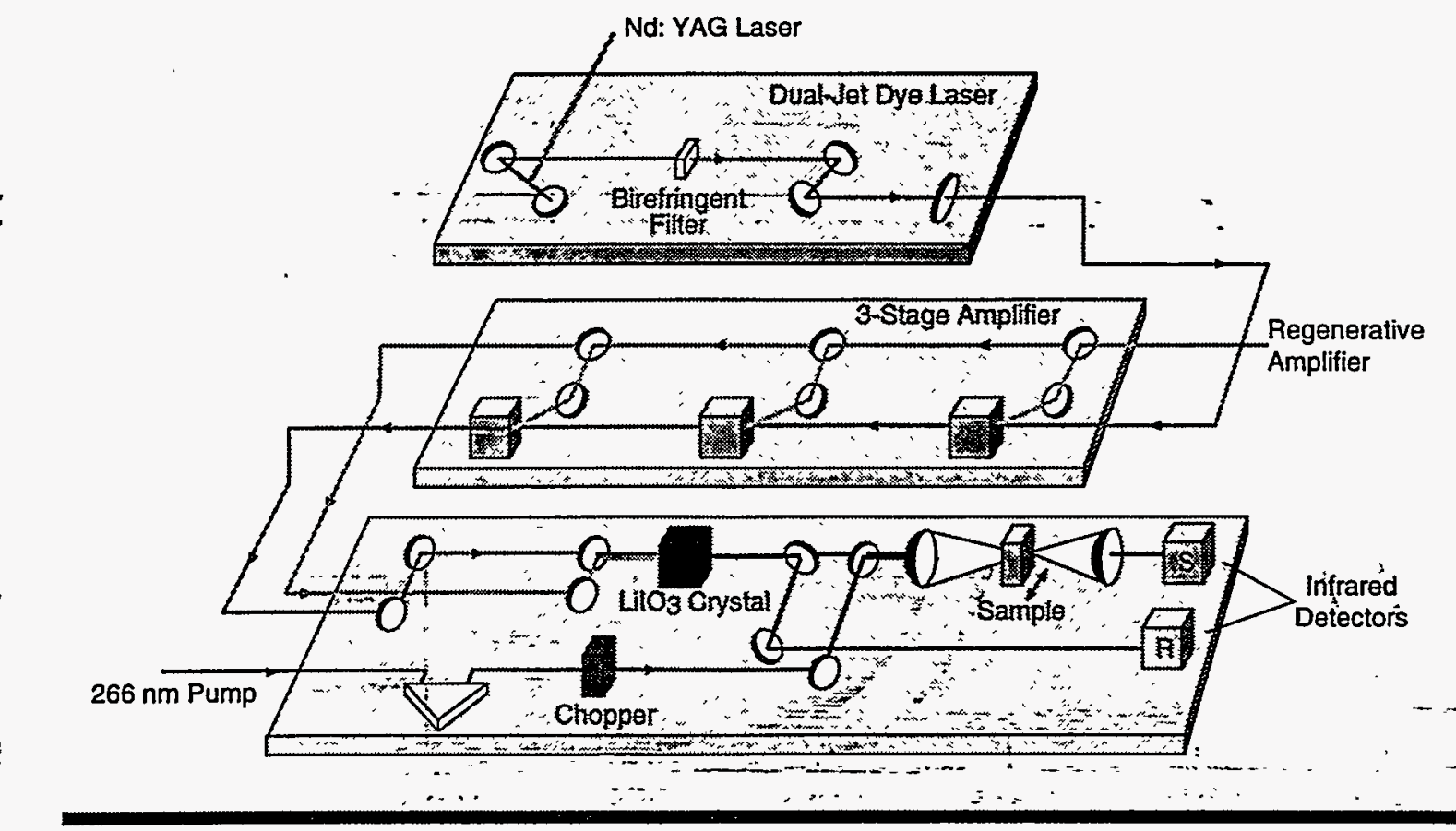

Figure 1: Schematic of the exprimental set-up.

\section{RESULTS}

The change of the $\mathbb{R}$ absorbance was monitored in the diazo/ketene region from 2120 to $2210 \mathrm{~cm}^{-1}$ at intervals of $10 \mathrm{~cm}^{-1}$. Maximum changes in absorption occurred at $2190 \mathrm{~cm}^{-1}$ where a decrease in absorbance was observed, and at $2150 \mathrm{~cm}^{-1}$ where an increase in absorbance was observed. We assign the $2190 \mathrm{~cm}^{-1}$ change to the bleaching of the diazo Meldrum's acid, and the $2150 \mathrm{~cm}^{-1}$ to the appearance of the keto-ketene intermediate. The decrease in absorbance at 2190 $\mathrm{cm}^{-1}$ occurs within our instrument response and is constant for $6 \mathrm{~ns}$ as expected for the photodissociation. Similarly, the rise time of the $2150 \mathrm{~cm}^{-1}$ feature we assign to the keto-ketene can also be described by our instrument response. Using deconvolution techniques we assign an upper limit on the appearance of the keto-ketene of $\tau<20 \mathrm{ps}$; no change was seen out to $6 \mathrm{~ns}$. In Fig. 2 is shown the difference spectra observed at $300-500$ ps, generated by averaging the 300 500 ps data in each of the kinetic traces. As the bands due to the starting diazo compound and the keto-ketene overlap significantly, we have fit the difference spectra to the difference of the DM infrared spectra and a gaussian function representing the keto-ketene.

The best fit yields a spectrum for the keto-ketene centered at $2161 \mathrm{~cm}^{-1}$ and with a width (FWHM) of $29 \mathrm{~cm}^{-1}$. Deviation from the experimental dată at some wavelengths suggests that the spectrum is more complex than a single gaussian as expected for dopants dispersed in polymeric matrices. The energy dependence of the-signal intensities (Fig. 3) was consistent with a single photon event, and:a:quantum yield of decomposition of $0.8 \pm 0.2 .18$ The quantum yield for the ketene appearance is about the same, suggesting that side reactions are not significant.

The linear dependence of the absorbance change over the applied energy range, varying from below to above the threshold of ablation $(\approx 70 \mu \mathrm{J})$, suggests that ablation take not place during this time scale ( $6 \mathrm{~ns})$. The ejection of material would be expected to alter the observed signal due to scattering. 


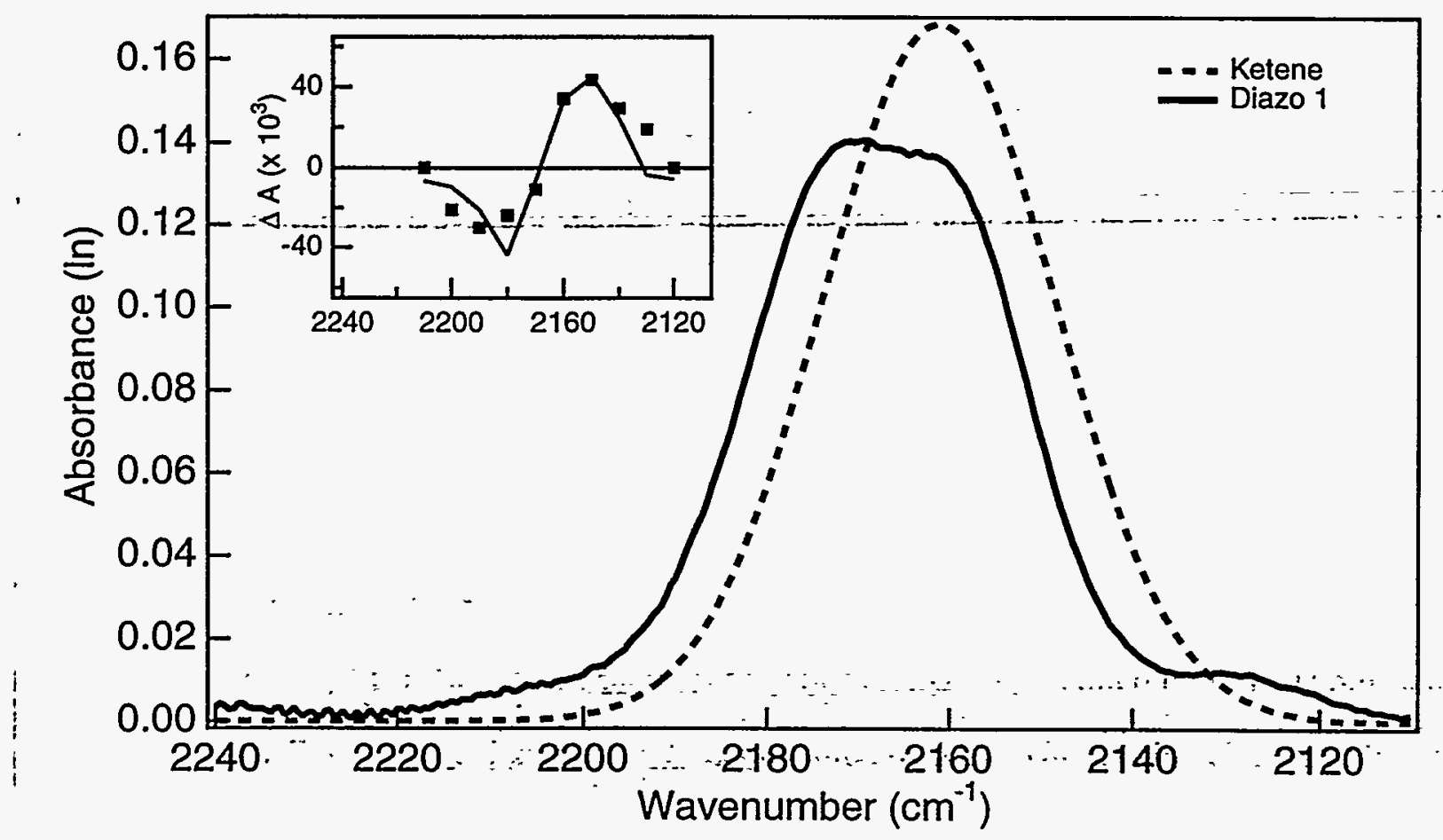

Figure 2: Spectra of DM (solid line), and the keto-ketene (dashed line) at $300-500$ ps calculated by fitting the difference spectrum (inset) to the difference of the DM spectra and a gaussian function which best represents the ketene spectrum. The fit which results from the difference of the two spectra is shown in the inset.

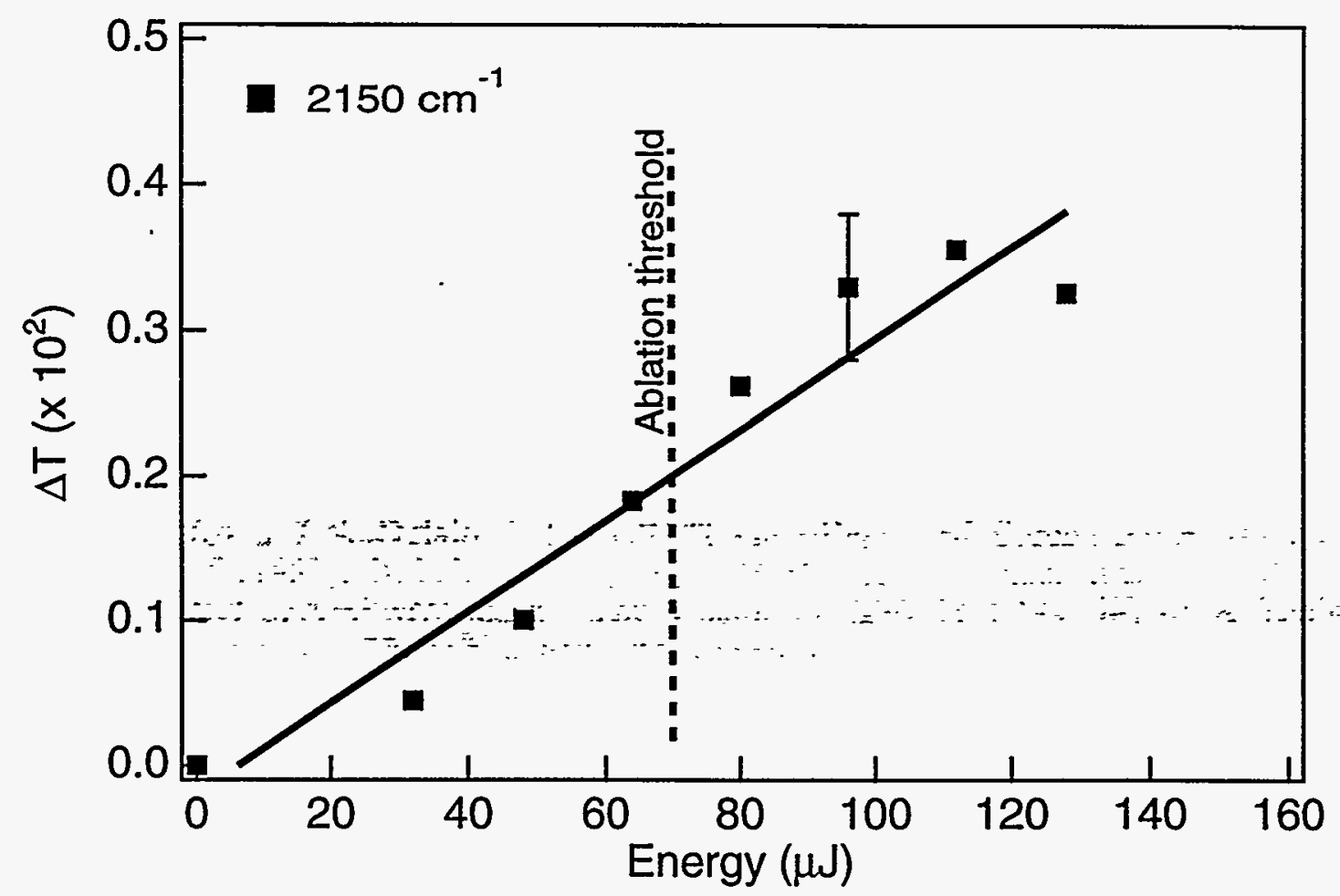

Figure 3: Dependence of the signal intensity on the laser energy $(266 \mathrm{~nm})$. 


\section{CONCLUSION}

In summary, these experiments have provided the first example of how ultrafast infrared spectroscopy may be used to examine laser-driven reactions in polymeric matrices. We have determined that the photoinduced Wolff rearrangement of DM in a PMMA matrix is complete within $20 \mathrm{ps}$. The $\mathbb{I}$ band assignable to the ketene is centered at $2161 \mathrm{~cm}^{-1}$ and has a width of 29 $\mathrm{cm}^{-1}$. The rapid formation of the ketene is a key element of the high quantum yield of carboxylic acid formation, and for the use of DM as an ablation sensitizer. The power dependence data show that ablation doesn't appear within 6 ns. Future experiments will center on extending our wavelength range so that we may observe the ketone moieties, and hopefully the keto-carbene itself, and on examining the effect of different matrices. Finally, in the near future we will be extending our measurements to examine a variety of other processes (e.g. ablation, curing, etc.) for which detailed structural information on ultrafast timescales has technological importance.

\section{REFERENCES}

(1) (a) M. J. Bowden, Materials for Microlithography edited by L: F. Thompson, C. G. Willson, J. M. J. Frechet, (A. C. S. Symposium Series 266, 1984), pp 39. (b) E. Reichmanis, C. W. Wilkins, Microelectronic Polymers, edited by M. S. Htoo, (Marcel Dekker Inc. New York, 1989), pp. 1-66. (c) D. S. Soane and Z. Martynenko, Polymers in Microelectronics, (Elsevier Amsterdam, 1989) pp 1-276.

(2) (a) J. Pacansky and D. J. Johnson, J. Electrochem. Soc. 124, 862 (1977),. (b) J. Pacansky and J. Lyerla, I. B. M. J. Res. Develop. 23, 42 (1979). (c) J. Pacansky, Polymer Eng. Sci. 20, 1049 (1980).

(3) See, for example: (a) T. Lippert, J. Stebani, J. Ihlemann, O. Nuyken, and A. Wokaun, Angew. Makromol. Chem. 213, 127 (1993). (b) H. Hiraoka and S. Lazare, Appl. Surf. Sci. 46, 342 (1990). (c) H. Fukumura, S. Mibuka, S. Eura, H. Masuhara and N. Nishi, J. Phys. Chem. 97, 13761 (1993). (d) R. Srinivasan and B. Braren, Appl. Phys. A45, 289 (1988). (e) C. R. Davis, F. D. Egitto and S. L. Buchwalter, Appl. Phys. B54, 227 (1992). (f) Y. Kawamura, K. Toyoda and S. Namba, Appl. Phys. Lett. 40, 374 (1982).

(4) Widely used in this regard are a variety of diazonaphthoquinones in Novalak resins, including the commercially available naphthoquinone diazides (Shipley-AZ1350J, Kodak-Photoresist 820, Hunt-HPR 204). See: J. F. Rabek, Mechanism of Photophysical Processes and Photochemical Reactions in Polymers, (John Wiley \& Sons, Chichester, 1987), pp. 413-464.

(5) Wolff rearrangements are widely used for various synthetic applications. See, for example: (a) D. Redmore and C. D. Gutsche, Adv. Alicyclic Chem. 3, 125 (1971). (b) J. March, Advanced Organic Chemistry: (McGraw-Hill: New York, 1985), p. 974.

(6) (a) J. A. Delaire, J. Faure, F. Hassine-Renou, M. Soreau and A. Mayeaux, Nouv. J. Chim. 11, 15 (1987). (b) J. J. M. Vleggaar, A. H. Huizer, P. A. Kraakman, W. P. M. Nijssen, R. J. Visser and C. A. G. O. Varma, J. Am. Chem. Soc. 116, 11754 (1994). (c) K. Tanigaki and T. W. Ebbesen, J. Phys. Chem. 93, 4531 (1989).

(7) A key component of our program is to study reactions directly in the polymer matrix. In the case of diazoketones in particular, the reactivity can be completely different in solution. For example, in methanol the product after $\mathrm{N}_{2}$ loss is Meldrum's acid: I. Hayashi, T. Okada and M. Kawanishi, Bull. Chem. Soc., Jpn. 43,2506 (1970). 
(8) (a) C. G. Willson, N. J. Clecak, B. D. Grant and R. J. Twieg, Electrochem. Soc. Preprints 696 (1980). (b) B. D. Grant; N. J. Clecak, R. J. Twieg and C. G. Willson, IEEE Trans. Electron Devices 28, 1300, (1981). (c) C. G. Willson, R. D. Miller and D. R. McKean, Proc. SPIE. (Advances in Resist Technol. and Processing IV), 771 (1987).

(9) H. Fujiwara, Y. Nakajima, H. Fukumura and H. Masuhara, J. Phys. Chem. 99, 11481 (1995).

(10) (a) J. Andraos, Y. Chiang, C. G. Huang, A. J. Kresge and J. C. Scaiano, J. Am. Chem. Soc. 115, 10605 (1993). (b) M. Barra, T. A. Fisher, G. J. Cernigliaro, R. Sinta and J. C. Scaiano, J. Am. Chem. Soc. 114, 2630 (1992).

(11) (a) V. A. Nikolaev and N. N. Khimich, Chim. geterotsikl. Soed. 321 (1985). (b) T. Livinghouse and R. J. Stevens, J. Am. Chem. Soc. 100, 6479 (1978). (c) E. Voigt and H. Meier, Chem. Ber. 108, 3326 (1975).

(12) (a) reference 4c. (b) K. Tangaki and T. W. Ebbesen, J. Am. Chem. Soc. 109, 5583 (1987).

(c) W. J. Bouma, R. H. Nobes, L. Radom and C. E. Woodward, J. Org. Chem. 47, 1869 (1982).

(d) K. Tanaka and M. J. Yoshimine, J. Am. Chem. Soc. 102, 7655 (1980).

(13) M. A. Winnik, F. Wang, T. Nivaggioi, Z. Hruska, H. Fukumura and H. Masuhara, J. Am. Chem. Soc. 113,. 9702 (1991).

(14) M. Ulbricht, J.-U. Thurner, M. Siegmund and G. Tomaschewski, Z. Chem. 28, 102 (1988).

15(15) Commercial photoresists typically use Novolak resin as the polymer matrix. Here, we have choosen PMMA to avoid having the matrix absorb some of the UV excitation pulse. Later studies will examine the effect of different matrices.

(16) (a) S. K. Doorn, R. B. Dyer, P. O. Stoutland and W. H. Woodruff, J. Am. Chem. Soc. 115, 6398 (1993). (b) P. O. Stoutland, R. B. Dyer and W. H. Woodruff, Science 257, 1913 (1992).

(17) A typical film was prepared by dissolving $750 \mathrm{mg}$ of PMMA, and $200 \mathrm{mg}$ of DM in $15 \mathrm{~mL}$ of THF. This was coated onto a polypropylene sheet (0.5 - $1.0 \mathrm{~mm}$ thick) with a \#20 Mayer rod (wet thickness $\sim 50 \mu \mathrm{m}$ ). These were dried in air and stored in the dark. Monitoring the films with UV-vis and IR spectroscopy showed no decomposition over 2 weeks.

(18) This agrees with the previously reported values of 0.6 and 1.0: references 9, and 13 .

\title{
DISCLAIMER
}

\begin{abstract}
This report was prepared as an account of work sponsored by an agency of the United States Government. Neither the United States Government nor any agency thereof, nor any of their employees, makes any warranty, express or implied, or assumes any legal liability or responsibility for the accuracy, completeness, or usefulness of any information, apparatus, product, or process disclosed, or represents that its use would not infringe privately owned rights. Reference herein to any specific commercial product, process, or service by trade name, trademark, manufacturer, or otherwise does not necessarily constitute or imply its endorsement, recommendation, or favoring by the United States Government or any agency thereof. The views and opinions of authors expressed herein do not necessarily state or reflect those of the United States Government or any agency thereof.
\end{abstract}

